\title{
The Role of Social Work in the Aftermath of Disasters and Traumatic Events
}

\author{
Jennifer Bauwens $^{1} \cdot$ April Naturale $^{2}$
}

Published online: 27 April 2017

(C) Springer Science+Business Media New York 2017

Over the past 15 years, in the United States, there has been an estimated $40 \%$ increase in federally declared disasters (FEMA 2016a, b). These numbers are even higher on the international scene, where natural disasters have doubled over the past two decades (IFRCRC 2016; Holmes 2008). Global armed conflict has been on the rise (IRC 2015), and has resulted in an increase in traumatic exposure and experiences for civilians and soldiers alike. The rise in armed conflict has been equated with an increase in refugees, with some estimates counting a million individuals and families that have been affected (IFRCRC 2016; IRC 2016). For many refugees, there seems to be no imminent resolution in sight, particularly for those coming from the Middle East.

With a growing number of people facing traumatic events, it is important, as a profession, we are clear about the role social workers have in the disaster planning, response, and recovery phases. In fact, social work, as a profession, has already played an important role in the disaster field, as many are informed, trained, and experienced in the basic skills necessary to respond. This is evidenced by the fact that nearly half of the disaster mental health services, in the U.S., have been delivered by social workers who are affiliated with the American Red Cross and the Federal Crisis Counseling Assistance and Training programs (ARC 2016; FEMA 2016a, b).

Jennifer Bauwens

jb1316@scarletmail.rutgers.edu

April Naturale

April.Naturale@icfi.com

1 Rutgers, the State University of New Jersey, 536 George Street, New Brunswick, NJ 08901, USA

2 New York University, Silver School of Social Work, 1 Washington Square N, New York, NY 10003, USA
Importantly, social workers have the potential to bring a unique understanding to the disaster field by underscoring the values of our profession and giving attention to oppressed and disadvantaged populations. This perspective is vital for the development of individual, family, and community response plans. Additionally, the social work perspective is needed for conducting research after a disaster or traumatic event. In other words, the social work profession needs to have a voice in a budding field that is lacking, but developing, interventions, research, and empirical evidence to guide our disaster-related responses.

Given the increase in all types of communal disasters, it's no surprise that other disciplines have also acknowledged the need to firm up our concepts and theories, response plans and interventions, and to solidify, best practices and evidence-based responses at the micro to macro levels. In an effort to provide greater conceptual clarity for the experiences of disaster survivors, psychologists from the National Center for Posttraumatic Stress Disorder took a first step and defined a disaster as, "a sudden event that has the potential to terrify, horrify or engender substantial losses for many people simultaneously" (Norris 2002, p. 1). This definition was later expanded to identify the type of disaster as natural or weather related, human caused accidents (i.e., technological), intentionally caused (i.e., terrorism and mass violence), and armed conflict/war (IFRC 2016; SAMHSA 2016).

Defining a "disaster" was an essential first step, as this concept outlined a necessary distinction between different types of disasters. This distinction is important because it incorporates the evidence which suggests that there is, indeed, a difference in the traumatic responses that accompany the nature of a disaster (e.g., Norris et al. 2002). Further, our current definition has helped shape how we approach and develop interventions, response plans, and 
conduct research to advance the field. As the definition of disaster dictates, a one-size-fits-all intervention plan may not always be appropriate. Interventions, then, need to be implemented with consideration to the type of disaster, but also with attention to the phase in which the interventions will be delivered (i.e., acute, long-term ), the geographic area(s) affected by the event (i.e., block, city, state), the scope (i.e., number of people killed, injured, the level of destruction), and other known risk factors for negative social and psychological sequelae post-disaster (i.e., trauma and psychiatric history).

Taken together, this means the skills and knowledge required to respond to disasters, of all types, are vastly different than traditional clinical skills, psychotherapy, or trauma treatment. For example, contacts with disaster survivors, particularly immediately after an event, are generally held at a Family Assistance Center or another community or faith based location. Meetings are often time limited (i.e., sometimes as little as one session). In this case, the goal is symptom reduction, psychoeducation, and providing resources and referrals. This is vastly different than a first session characteristic of most types of clinical work. That is, with traditional trauma-focused clinical modalities, the focus of an initial session is likely to be on establishing trust in effort to promote disclosure of an earlier traumatic experience. Regardless if the clinical model is long- or short-term, the goal, in part, is for the client to share their trauma narrative, but with greater detail than is afforded in disaster work.

Disaster practices, on the other hand, can be further differentiated from clinical work by the tendency to necessarily intervene immediately or shortly after the disaster or traumatic event. Aside from the obvious, another reason for disaster interventions to primarily focus on the shortterm may be related to the developmental phase of the field, which is in the infancy stage. For this reason, the field has a lot of unanswered questions and unaddressed areas that require further investigation. For example, it is clear, as we are learning from the Oklahoma City bombing and the events of September 11, 2001, that complications may develop over the long-term (e.g., Neria et al. 2007). Nonetheless, research and response plans have focused primarily on the most pressing issues, in this case, the immediate needs of survivors.

Again, by comparison, advances have been made toward building a solid base of evidence to support many traumafocused interventions (e.g., NCPTSD 2016). This is not the case, however, when it comes to disaster response practices. Routinely used practices such as, psychological first aid, crisis intervention and counseling, critical incident stress debriefing, mental health media communications, family care, resilience and community capacity building, and many other support activities, play a vital role in a comprehensive disaster mental health response program. These practices are employed with minimal research to inform their use.

Another reason for the lack of evidence to support regularly used disaster mental health practices rests in the fact that this type of research can be difficult to conduct. Some may even consider it controversial or inappropriate to ask trauma survivors, family members, and responders to participate in a study amid their emotional distress, loss, and grief. Additionally, there might be challenges to conducting the research itself. In most instances, researchers conducting clinical studies have access to a clinic, hospital, or nonprofit organization. For disaster researchers, there may not be a formal gatekeeper to help connect the scientific community to affected responders, individuals, and families to involve them in study. For now, and until research findings are strengthened in the disaster field, social workers and clinicians can glean from theory, expert consensus, white papers, and anecdotal reports to inform their interventions. In this case, these sources provide the best evidence available to determine the most effective intervention given the current state of the field. As a starting point, the criterion for selecting an intervention is simply one that promises to do "no harm."

The purpose, then, of this special issue is to inform social workers and clinicians concerning a wide-range of topics associated with the social and psychological affects that follow different types of disasters. Some of the articles included in this issue will contribute theory, case study, anecdotal and empirical evidence, and introduce new concepts and interventions pertinent to the disaster discourse. The areas covered in this issue focus on developing community resilience, the presence of domestic violence after a large-scale traumatic event, a narrative from a disaster researcher who survived a house fire, and a review of the qualitative literature on the long-term effects of families who lost a loved one following September 11, 2001. This issue is also aimed at bringing the reader up-to-date with the latest advances and thought surrounding micro and macro interventions, for children, schools, and communities. These articles discuss educating students about disaster response, how to develop a cadre of university student responders, supporting children who are high risk after a traumatic event, a case review of lessons learned from a program applied to the Boston Marathon bombing (Naturale et al. 2017), and a framework for enhancing community resilience. These papers, although varied, highlight the uniqueness of the disaster field. Every article included in this issue is expected to help social workers and other professionals to be aware of the multi-faceted issues facing those who respond, and those who will respond, to do so effectively and appropriately in the unfortunate, but inevitable, event of a disaster. 


\section{References}

American Red Cross. (2016). Retrieved November 4, 2016 from http:// www.redcross.org/about-us/history/global-red-cross-network.

Federal Emergency Management Agency. (2016a). Retrieved November 17, 2016 from https://www.fema.gov/disasters/grid/year.

Federal Emergency Management Agency. (2016b). Crisis Counseling Assistance and Training Program. Retrieved from: https://www. fema.gov/media-library-data/1465330831840-a8641fe39cbaad835f9ba670d082c1d9/FACT_SHEETCrisis_Counseling_Program2016.pdf.

Holmes, J. (2008). More help now please: How to tackle tomorrow's disasters. The Economist, 110.

International Federation of Red Cross. (2016). Types of disasters: Definition of hazard. Retrieved November 17, 2016 from http://www.ifrc.org/en/what-we-do/disaster-management/ about-disasters/definition-of-hazard/.

International Federation of Red Cross and Red Crescent Societies. (2016). World Disasters Report. Retrieved from http://ifrcmedia.org/interactive/wp-content/uploads/2015/09/1293600World-Disasters-Report-2015_en.pdf and http://www.ifrc.org/.

International Rescue Committee. (2015). Annual Report. Retrieved from http://feature.rescue.org/annual-report-2015/.

International Rescue Committee. (2016). Retrieved November 16, 2016 from https://www.rescue.org/topic/refuge-america?gclid $=$ Cj0KEQiA08rBBRDUn4qproqwzYMBEiQAqpzns0oT23MVln8-8VqBiPw_rKlhUorLGZ0mjje0Knto9VsaAtiw8P8HAQ.

National Center for Posttraumatic Stress Disoder. (2016). Retrieved November 17, 2016 from http://www.ptsd.va.gov/professional/ trauma/disaster-terrorism/index.asp.
Naturale, A., Lowney, L. T., \& Brito, C. S. (2017). Lessons learned from the Boston Marathon bombing victim services program. Clinical Social Work Journal, 45(2). doi:10.1007/ s10615-017-0624-7

Neria, Y., Gross, R., Litz, B., Maguen, S., Insel, B., Seirmarco, G., et al. (2007). Prevalence and psychological correlates of complicated grief among bereaved adults 2.5-3.5 years after September 11th attacks. Journal of Traumatic Stress, 20, 251-262. doi: $10.1002 /$ jts. 20223.

Norris, F. (2002). Psychosocial consequences of disaster. PTSD Quarterly, 13(2), 1-3.

Norris, F. H., Friedman, M. J., Watson, P. J., Byrne, C. M., Diaz, E., \& Kaniasty, K. (2002). 60,000 disaster victims speak: An empirical review of the empirical literature, 1981-2001. Psychiatry, 65, 207-239. doi:10.1521/psyc.65.3.207.20173.

Substance Abuse and Mental Health Services Administration. (2016). Crisis Counseling Assistance and Training Program Core Content Training. Retrieved from http://www.samhsa.gov/dtac/ ccp-toolkit/train-your-ccp-staff/core-content-training.

Jennifer Bauwens Ph.D., LCSW has worked, both nationally and internationally, with children and adult survivors of disasters, abuse, and other traumatic events. She currently consults with nonprofits to develop evaluation tools and trauma-informed curriculums and trainings, and she teaches courses on research and trauma at Rutgers, The State University of New Jersey.

April Naturale Ph.D., is a trauma specialist at ICF and architect of the marathon bombing behavioral health response. She directed the mental health response to $9 / 11$ in NY. 